\title{
SOLUSI NUMERIK PERSAMAAN POISSON MENGGUNAKAN JARINGAN FUNGSI RADIAL BASIS PADA KOORDINAT POLAR
}

\author{
Fatma Mufidah, Mohammad Jamhuri \\ Jurusan Matematika UIN Maulana Malik Ibrahim Malang \\ e-mail:fatma.mufida@gmail.com, m.jamhuri@live.com
}

\begin{abstract}
ABSTRAK
Persamaan Poisson dalam koordinat polar atau lingkaran merupakan persamaan diferensial parsial linier orde dua tipe eliptis. Persamaan ini merupakan bentuk non homogen dari persamaan Laplace. Persamaan Poisson pada koordinat polar disini menggambarkan distribusi panas dalam ruang, yang dalam hal ini berbentuk lingkaran. Solusi numerik persamaan Poisson diperoleh dengan metode jaringan fungsi radial basis. Dengan metode ini, setiap fungsi dan turunannya dapat didekati secara langsung dengan sebuah fungsi basis. Fungsi basis yang digunakan adalah fungsi basis jenis multiquadrics. Solusi numerik menggunakan metode jaringan fungsi radial basis khususnya metode langsung yang diperoleh dari penelitian ini menunjukkan keakuratan yang tinggi dengan diperolehnya galat yang relatif kecil. Dengan galat mutlak maksimum terkecil yaitu 0,00088, dengan pemilihan $\Delta r=0,1$ dan $\Delta \theta=\frac{\pi}{45}$. Ini menunjukkan bahwa metode jaringan fungsi radial basis cukup efektif dalam mengaproksimasi persamaan Poisson dengan domain lingkaran.
\end{abstract}

Kata kunci: Solusi Numerik, Persamaan Poisson, Jaringan Fungsi Radial Basis, Koordinat Polar.

\begin{abstract}
Poisson equation on the polar coordinate is one of the second order partial differential equations of elliptic type. This equation is also a special case of Laplace equation and inhomogeneous version of Laplace equation. Poisson equation here describes heat conduction on the polar region. Here, we solve Poisson equation using radial basis function networks with multiquadrics as a basis function. Numerical experiments show that radial basis function network achieves great accuracy. The smallest maximum absolute errors is 0,00088 with $\Delta r=0,1$ and $\Delta \theta=\frac{\pi}{45}$. From this result, it can be concluded that radial basis function networks method is effective to approximate Poisson equation on the polar coordinate.
\end{abstract}

Keywords: Numerical Solution, Poisson Equation, Radial Basis Function Networks, Polar Coordinate.

\section{PENDAHULUAN}

Persamaan Poisson merupakan persamaan diferensial parsial orde dua tipe eliptis yang implementasinya banyak digunakan dalam teknik elektro, teknik mesin, dan fisika teori. Dinamai dari nama belakang seorang matematikawan Perancis yang juga seorang ahli fisika dan geometri Siméon Denis Poisson. Dalam fisika teori, persamaan Poisson menggambarkan distribusi panas dalam ruang.

Salah satu metode numerik yang digunakan dalam menyelesaikan masalah persamaan diferensial adalah jaringan fungsi radial basis (Radial Basis Function Networks). Dengan metode ini, setiap fungsi dan turunannya dapat didekati secara langsung dengan sebuah fungsi basis. Jaringan fungsi radial basis telah lama dikenal dalam bidang rekayasa dan teknik sebagai jaringan syaraf tiruan yang menggunakan fungsi basis sebagai fungsi pengaktif. Gagasan jaringan fungsi radial basis diperoleh dari teori aproksimasi fungsi. Mengaproksimasi suatu fungsi adalah menghampiri fungsi tersebut dengan fungsi lainnya.
Jaringan fungsi radial basis merupakan pemetaan dari suatu vektor input dengan $p$-dimensi ke vektor output yang hanya 1 dimensi. Secara aljabar disimbolkan dengan $f: R^{p} \rightarrow R^{l}$. Fungsi $f$ terdiri dari himpunan bobot $\left\{w_{j}\right\}_{j=1}^{m}$ dan himpunan fungsi basis $\left\{\phi\left(x_{i}, c_{j}\right)\right\}_{j=1}^{m}$, dengan $\left\{x_{i}\right\}_{i=1}^{n}$. Secara umum, fungsi basis dapat ditulis dengan $\phi\left(x_{i}, c_{j}\right)=$ $\sqrt{\left(x_{i}-c_{j}\right)^{2}+\alpha^{2}}, \alpha=\operatorname{var}(x) \cdot x_{i}$ adalah vektor input dan $c_{j}$ adalah titik center dari $x$ ke- $i$ [3].

Koordinat Cartesius bukan merupakan satusatunya jalan untuk menunjukkan kedudukan suatu titik pada bidang. Karena bentuk geometris di alam tidak selalu berupa kotak-kotak atau persegi panjang, namun adakalanya berbentuk lingkaran. Sehingga sistem koordinat Cartesius menjadi terbatas penggunaannya. Cara lain ialah menggunakan sistem koordinat polar. 


\section{KAJIAN PUSTAKA}

\section{Persamaan Poisson}

Strauss [6] menyatakan bahwa jika sebuah persamaan difusi atau persamaan gelombang tidak bergantung pada waktu $(t)$, yaitu $u_{t}=0$ dan $u_{t t}=0$, maka persamaan difusi dan persamaan gelombang tersebut menghasilkan persamaan Laplace. Persamaan Poisson merupakan bentuk non homogen dari persamaan Laplace.

$$
\nabla^{2} u=f
$$

Dengan $f$ adalah sebuah fungsi yang diberikan, maka disebut persamaan Poisson.

Bentuk umum persamaan Poisson dalam dua dimensi dalam koordinat Cartesius yaitu:

$$
\frac{\partial^{2} u(x, y)}{\partial x^{2}}+\frac{\partial^{2} u(x, y)}{\partial y^{2}}=f(x, y)
$$

Pada domain $\boldsymbol{x}_{\boldsymbol{a}}<\boldsymbol{x}<\boldsymbol{x}_{\boldsymbol{b}}, \boldsymbol{y}_{\boldsymbol{a}}<\boldsymbol{y}<\boldsymbol{y}_{\boldsymbol{b}}$.

Boyce dan DiPrima [1] menyatakan bahwa masalah kondisi batas untuk persamaan Poisson 2 dimensi $(\boldsymbol{x}, \boldsymbol{y})$ dalam sistem koordinat Cartesius adalah:

$$
\begin{aligned}
& u\left(x_{a}, y\right)=f_{1}(y) \\
& u\left(x_{b}, y\right)=f_{2}(y) \\
& u\left(x, y_{a}\right)=f_{3}(x) \\
& u\left(x, y_{b}\right)=f_{4}(x)
\end{aligned}
$$

Dengan $\boldsymbol{f}_{\mathbf{1}}(\boldsymbol{y}), \boldsymbol{f}_{\mathbf{2}}(\boldsymbol{y}), \boldsymbol{f}_{\mathbf{3}}(\boldsymbol{x}), \boldsymbol{f}_{\mathbf{4}}(\boldsymbol{x})$ adalah fungsifungsi yang menyatakan kondisi pada batas-batas tersebut.

Persamaan Poisson pada sistem koordinat polar $(\boldsymbol{r}, \boldsymbol{\theta})$, dengan $\boldsymbol{u}(\boldsymbol{r}, \boldsymbol{\theta})$ adalah:

$$
\frac{\partial^{2} u(r, \theta)}{\partial r^{2}}+\frac{1}{r} \frac{\partial u(r, \theta)}{\partial r}+\frac{1}{r^{2}} \frac{\partial^{2} u(r, \theta)}{\partial \theta^{2}}=f(r, \theta)
$$

Dengan domain $\mathbf{0}<\boldsymbol{r}<\boldsymbol{a}$ dan $\mathbf{0} \leq \boldsymbol{\theta} \leq \boldsymbol{b}$. Masalah kondisi batas untuk persamaan Poisson yang domainnya berupa lingkaran $(\boldsymbol{r}, \boldsymbol{\theta})$, kondisi batas harus berupa kondisi pada tepi dan pusat lingkaran yaitu:

$$
\begin{aligned}
& \boldsymbol{u}(\boldsymbol{a}, \boldsymbol{\theta})=\boldsymbol{f}(\boldsymbol{\theta}) \\
& \boldsymbol{u}(\mathbf{0}, \boldsymbol{\theta})=\boldsymbol{f}(\boldsymbol{\theta})
\end{aligned}
$$

Dengan $a$ adalah jari-jari lingkaran dan $f(\theta)$ adalah fungsi yang menyatakan kondisi pada batas tersebut.

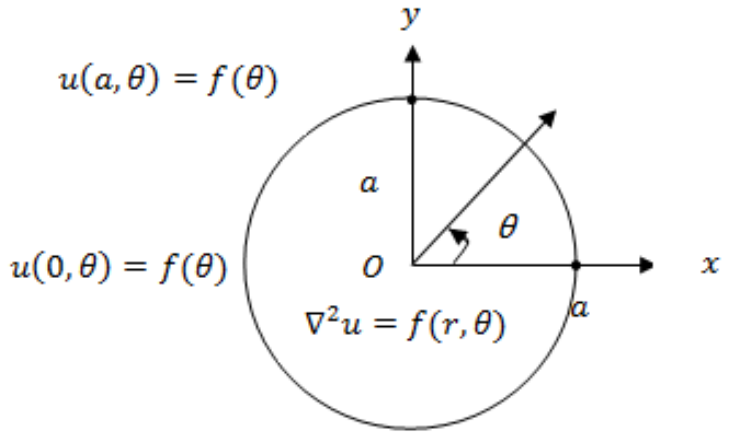

Gambar 1 Kondisi Batas pada Koordinat Polar

\section{Sistem Koordinat Polar}

Pada sistem koordinat polar, sepasang koordinat polar suatu titik ditulis dengan $(r, \theta)$. Sebagai ilustrasi sistem koordinat polar, kita mulai dengan menggambar sebuah setengah garis tetap yang dinamakan sumbu polar yang berpangkal pada sebuah titik pusat $O$. Titik ini disebut polar atau titik asal. Biasanya sumbu polar ini kita gambar mendatar dan mengarah ke kanan dan oleh sebab itu sumbu ini dapat disamakan dengan sumbu $x$ positif pada sistem koordinat Cartesius.

Setiap titik $P$ adalah perpotongan antara sebuah lingkaran tunggal yang berpusat di $O$ dan sebuah sinar tunggal yang memancar dari $O$. Jika $r$ adalah jari- jari ingkaran dan $\theta$ adalah salah satu sudut antara sinar dan sumbu polar. Maka yang dinamakan sepasang koordinat polar dari titik $P$ dan ditulis dengan $P(r, \theta)$ adalah $(r, \theta)[7]$.

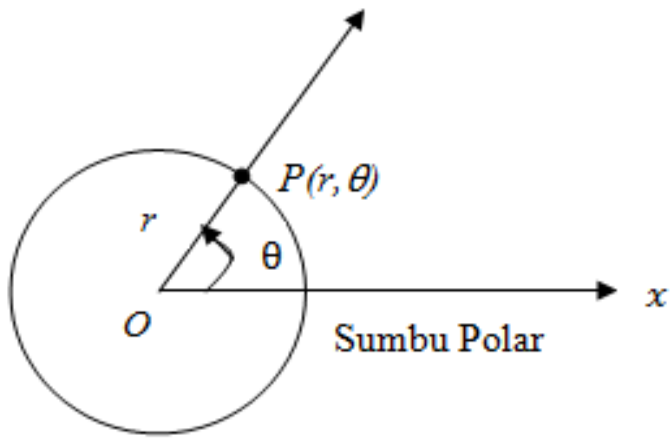

Gambar 2 Sistem Koordinat Polar

Purcell dan Varberg [7] menyatakan bahwa andaikan sumbu polar berimpit dengan sumbu $x$ positif pada sistem koordinat Cartesius. Maka koordinat polar $(r, \theta)$ sebuah titik $P$ dan koordinat Cartesius $(\boldsymbol{x}, \boldsymbol{y})$ titik itu dihubungkan oleh persamaan:

$$
\begin{gathered}
x=r \cos \theta \\
y=r \sin \theta \\
r^{2}=x^{2}+y^{2} \\
\tan \theta=\frac{y}{x} \\
\theta=\arctan \frac{y}{x}
\end{gathered}
$$

\section{Jaringan Fungsi Radial Basis}

Jaringan fungsi radial basis mulai dikenal pertama kali sejak D. S. Broomhead dan David Lowe menyampaikan makalahnya yang berjudul Radial basis functions, Multi-variable functional interpolation and adaptive networks pada tahun 1988 [2]. Jaringan fungsi radial basis merepresentasikan sebuah pemetaan dari vektor input dengan $p$-dimensi ke vektor output yang hanya 1-dimensi. Secara matematis jaringan fungsi radial basis ditulis dengan $f: R^{p} \rightarrow R^{l}[5]$.

Fungsi $f$ pada $f: R^{p} \rightarrow R^{1}$ terdiri dari himpunan bobot $\left\{w_{j}\right\}_{j=1}^{m}$ dan himpunan fungsi basis 
$\left\{\phi\left(r_{i}, \theta_{i}\right)\right\}_{i=1}^{n}$, dengan $\left\{r_{i}\right\}_{i=1}^{n}$ dan $\left\{\theta_{i}\right\}_{i=1}^{n}$. Secara umum, fungsi basis dapat ditulis dengan $\phi\left(r_{i}, c_{j}\right)=\sqrt{\left(r_{i}-c_{j}\right)^{2}+\alpha}, \alpha=\operatorname{var}\left(r_{i}\right) \cdot r_{i}$ adalah vektor input dan $c_{j}$ adalah titik center dari $r$ ke- $i$ [3].

Fungsi basis untuk 2 variabel $(r, \theta)$ :

$$
\frac{\phi\left(r_{i}, \theta_{i}, c_{j}, d_{j}\right)=}{\sqrt{\left(r_{i}-c_{j}\right)^{2}+\left(\theta_{i}-d_{j}\right)^{2}+\beta}}
$$

$\beta=\frac{\operatorname{var}\left(r_{i}\right)+\operatorname{var}\left(\theta_{i}\right)}{2}$

$r_{i}=$ vektor input ke- $i$

$\theta_{i}=$ vektor input ke- $i$

$c_{j}=$ titik center dari $r$ ke- $i$

$d_{j}=$ titik center dari $\theta$ ke- $i$

$\alpha=$ nilai parameter width untuk 1 variabel

$\beta=$ nilai parameter width untuk 2 variabel

\section{METODE PENELITIAN}

Metode yang digunakan dalam menyelesaikan secara numerik persamaan Poisson pada koordinat polar adalah menggunakan pendekatan studi literatur atau library research. Adapun langkah-langkah dalam penelitian ini adalah sebagai berikut:

a) Mentransformasi persamaan Poisson beserta kondisi batasnya dari koordinat Cartesius ke koordinat polar.

b) Menurunkan fungsi basis multiquadrics terhadap variabel-variabel bebasnya $(\boldsymbol{r}, \boldsymbol{\theta})$ hingga turunan kedua.

c) Mendiskritisasi persamaan Poisson pada koordinat polar menggunakan jaringan fungsi radial basis serta kondisi batasnya.

d) Mensubstitukan nilai-nilai input $\left(r_{i}, \theta_{i}\right)$ dan $f\left(r_{i}, \theta_{i}\right)$ ke dalam persamaan Poisson dalam bentuk persamaan jaringan fungsi radial basis yang telah diperoleh.

e) Menghitung nilai bobot $w_{j}$.

f) Menghitung solusi persamaan Poisson pada koordinat polar dengan mengalikan nilai bobot $w_{j}$ yang telah diperoleh dan fungsi basis multiquadrics yang tanpa diturunkan.

g) Melakukan simulasi, menggambarkan grafik, serta menganalisis galat.

h) Memberikan kesimpulan atas hasil penelitian yang telah diperoleh serta saran untuk penelitian selanjutnya.

\section{PEMBAHASAN}

\section{Transformasi Persamaan Poisson}

Transformasi persamaan Poisson dari koordinat Cartesius ke koordinat polar, dengan kaidah rantai (chain rule) diperoleh turunan pertama $u(x, y)$ persamaan (2) terhadap $x$ dan $y$.

$$
\begin{aligned}
& \frac{\partial u}{\partial x}=\frac{\partial u}{\partial r} \frac{\partial r}{\partial x}+\frac{\partial u}{\partial \theta} \frac{\partial \theta}{\partial x} \\
& \frac{\partial u}{\partial y}=\frac{\partial u}{\partial r} \frac{\partial r}{\partial y}+\frac{\partial u}{\partial \theta} \frac{\partial \theta}{\partial y}
\end{aligned}
$$

Kemudian turunan kedua $u(x, y)$ persamaan (2) terhadap $x$ dan $y$ diperoleh:

$$
\begin{gathered}
\frac{\partial^{2} u}{\partial x^{2}}=\frac{x^{2}}{r^{2}} \frac{\partial^{2} u}{\partial r^{2}}-2 \frac{x y}{r^{3}} \frac{\partial^{2} u}{\partial \theta \partial r}+\frac{y^{2}}{r^{3}} \frac{\partial u}{\partial r}+ \\
\frac{y^{4}}{r^{4}} \frac{\partial^{2} u}{\partial \theta^{2}}+\frac{2 x y}{r^{4}} \frac{\partial u}{\partial \theta} \\
\frac{\partial^{2} u}{\partial y^{2}}=\frac{y^{2}}{r^{2}} \frac{\partial^{2} u}{\partial r^{2}}+2 \frac{x y}{r^{3}} \frac{\partial^{2} u}{\partial \theta \partial r}+\frac{x^{2}}{r^{3}} \frac{\partial u}{\partial r}+ \\
\frac{x^{4}}{r^{4}} \frac{\partial^{2} u}{\partial \theta^{2}}-\frac{2 x y}{r^{4}} \frac{\partial u}{\partial \theta}
\end{gathered}
$$

Substitusi persamaan (13) dan (14) ke dalam persamaan (2):

$$
\frac{\partial^{2} u(x, y)}{\partial x^{2}}+\frac{\partial^{2} u(x, y)}{\partial y^{2}}=f(x, y)
$$

$\frac{x^{2}}{r^{2}} \frac{\partial^{2} u}{\partial r^{2}}-2 \frac{x y \partial^{2} u}{r^{3} \partial \theta \partial r}+\frac{y^{2} \partial u}{r^{3} \partial r}+\frac{y^{2} \partial^{2} u}{r^{4} \partial \theta^{2}}+\frac{2 x y \partial u}{r^{4} \partial \theta}+$

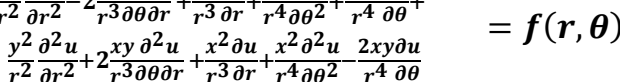

$\frac{x^{2}}{r^{2}} \frac{\partial^{2} u}{\partial r^{2}}+\frac{y^{2}}{r^{3}} \frac{\partial u}{\partial r}+\frac{y^{2}}{r^{4}} \frac{\partial^{2} u}{\partial \theta^{2}}+\frac{y^{2}}{r^{2}} \frac{\partial^{2} u}{\partial r^{2}}+\frac{x^{2}}{r^{3}} \frac{\partial u}{\partial r}+\frac{x^{2}}{r^{4}} \frac{\partial^{2} u}{\partial \theta^{2}}$

$\boldsymbol{f}(\boldsymbol{r}, \boldsymbol{\theta})$

$\left(\frac{x^{2}}{r^{2}}+\frac{y^{2}}{r^{2}}\right) \frac{\partial^{2} u}{\partial r^{2}}+\left(\frac{y^{2}}{r^{3}}+\frac{x^{2}}{r^{3}}\right) \frac{\partial u}{\partial r}+\left(\frac{x^{2}}{r^{4}}+\frac{y^{2}}{r^{4}}\right) \frac{\partial^{2} u}{\partial \theta^{2}}$

$$
\begin{aligned}
\left(\frac{x^{2}+y^{2}}{r^{2}}\right) \frac{\partial^{2} u}{\partial r^{2}}+\left(\frac{x^{2}+y^{2}}{r^{3}}\right) \frac{\partial u}{\partial r}+\left(\frac{x^{2}+y^{2}}{r^{4}}\right) \frac{\partial^{2} u}{\partial \theta^{2}} & =f(r, \theta) \\
\left(\frac{r^{2}}{r^{2}}\right) \frac{\partial^{2} u}{\partial r^{2}}+\left(\frac{r^{2}}{r^{3}}\right) \frac{\partial u}{\partial r}+\left(\frac{r^{2}}{r^{4}}\right) \frac{\partial^{2} u}{\partial \theta^{2}} & =f(r, \theta) \\
\frac{\partial^{2} u}{\partial r^{2}}+\left(\frac{1}{r}\right) \frac{\partial u}{\partial r}+\left(\frac{1}{r^{2}}\right) \frac{\partial^{2} u}{\partial \theta^{2}} & =f(r, \theta)
\end{aligned}
$$

Sehingga, persamaan Poisson dalam koordinat polar diperoleh persamaan (4). Dengan domain $0<r<a$ dan $0 \leq \theta \leq b$. Dan kondisi batas persamaan (5).

\section{Solusi Numerik Persaaan Poisson}

Langkah pertama untuk menghitung solusi numerik persamaan Poisson (4) menggunakan jaringan fungsi radial basis adalah mendiskritisasi persamaan Poisson (4). Karena persamaan Poisson (4) melibatkan turunan kedua $\boldsymbol{u}(\boldsymbol{r}, \boldsymbol{\theta})$ terhadap $\boldsymbol{r}$ dan $\boldsymbol{\theta}$, maka untuk menghampiri fungsi $\boldsymbol{u}(\boldsymbol{r}, \boldsymbol{\theta})$ pada persamaan Poisson (4), fungsi basisnya diturunkan dua kali terhadap $\boldsymbol{r}$ dan $\boldsymbol{\theta}$. Karena menggunakan metode langsung, sehingga fungsi basisnya diturunkan terhadap variabel bebasnya.

$$
u_{r}(r, \theta), \quad u_{r r}(r, \theta), \quad \text { dan } u_{\theta \theta}(r, \theta)
$$
digunakan untuk menghampiri fungsi $u(r, \theta)$ pada persamaan Poisson (4). Fungsi basis yang digunakan adalah jenis multiquadrics. 


$$
\begin{gathered}
u(r, \theta)=\sum_{j=1}^{m} w_{j} \phi\left(r, \theta, c_{j}, d_{j}\right) \\
\boldsymbol{u}_{r}(\boldsymbol{r}, \boldsymbol{\theta})=\sum_{j=1}^{m} \boldsymbol{w}_{j} \boldsymbol{\phi}_{r}\left(\boldsymbol{r}, \boldsymbol{\theta}, \boldsymbol{c}_{j}, \boldsymbol{d}_{j}\right) \\
\boldsymbol{u}_{r r}(\boldsymbol{r}, \boldsymbol{\theta})=\sum_{j=1}^{m} \boldsymbol{w}_{j} \phi_{r r}\left(\boldsymbol{r}, \boldsymbol{\theta}, \boldsymbol{c}_{j}, \boldsymbol{d}_{j}\right) \\
\boldsymbol{u}_{\boldsymbol{\theta}}(\boldsymbol{r}, \boldsymbol{\theta})=\sum_{j=1}^{m} \boldsymbol{w}_{j} \boldsymbol{\phi}_{\boldsymbol{\theta}}\left(\boldsymbol{r}, \boldsymbol{\theta}, \boldsymbol{c}_{j}, \boldsymbol{d}_{j}\right) \\
\boldsymbol{u}_{\boldsymbol{\theta} \theta}(\boldsymbol{r}, \boldsymbol{\theta})=\sum_{j=1}^{m} \boldsymbol{w}_{\boldsymbol{j}} \boldsymbol{\phi}_{\boldsymbol{\theta} \theta}\left(\boldsymbol{r}, \boldsymbol{\theta}, \boldsymbol{c}_{j}, \boldsymbol{d}_{j}\right)
\end{gathered}
$$

Dengan $\phi\left(r, \theta, c_{j}, d_{j}\right)$ diketahui pada persamaan (10), maka $\phi_{r}\left(r, \theta, c_{j}, d_{j}\right), \quad \phi_{r r}\left(r, \theta, c_{j}, d_{j}\right)$, $\phi_{\theta}\left(r, \theta, c_{j}, d_{j}\right)$ dan $\phi_{\theta \theta}\left(r, \theta, c_{j}, d_{j}\right)$ diperoleh:

$$
\begin{aligned}
& \phi_{r}\left(r, \theta, c_{j}, d_{j}\right)=\frac{r-c_{j}}{\sqrt{\left(r-c_{j}\right)^{2}+\left(\theta-d_{j}\right)^{2}+\beta}} \\
& \phi_{r r}\left(r, \theta, c_{j}, d_{j}\right)=\frac{\left(\theta-d_{j}\right)^{2}+\beta}{\left(\left(r-c_{j}\right)^{2}+\left(\theta-d_{j}\right)^{2}+\beta\right)^{\frac{3}{2}}} \\
& \phi_{\theta}\left(r, \theta, c_{j}, d_{j}\right)=\frac{\theta-d_{j}}{\sqrt{\left(r-c_{j}\right)^{2}+\left(\theta-d_{j}\right)^{2}+\beta}} \\
& \phi_{\theta \theta}\left(r, \theta, c_{j}, d_{j}\right)=\frac{\left(r-c_{j}\right)^{2}+\beta}{\left(\left(r-c_{j}\right)^{2}+\left(\theta-d_{j}\right)^{2}+\beta\right)^{\frac{3}{2}}}
\end{aligned}
$$

Untuk mengaproksimasi persamaan Poisson dalam koordinat polar menggunakan jaringan fungsi radial basis digunakan persamaan Poisson dalam bentuk persamaan jaringan fungsi radial basis. Dengan substitusi persamaan (16), (17), dan (18) ke dalam persamaan (4), maka: $\frac{\partial^{2} u(r, \theta)}{\partial r^{2}}+\frac{1}{r} \frac{\partial u(r, \theta)}{\partial r}+\frac{1}{r^{2}} \frac{\partial^{2} u(r, \theta)}{\partial \theta^{2}}=f(r, \theta)$ $\sum_{j=1}^{m} w_{j} \phi_{r r}\left(r, \theta, c_{j}, d_{j}\right)+\frac{1}{r} \sum_{j=1}^{m} w_{j} \phi_{r}\left(r, \theta, c_{j}, d_{j}\right)$ $+\frac{1}{r^{2}} \sum_{j=1}^{m} w_{j} \phi_{\theta \theta}\left(r, \theta, c_{j}, d_{j}\right)=f(r, \theta)$ $\sum_{j=1}^{m} w_{j}\left[\phi_{r r}\left(r_{i}, \theta_{i}, c_{j}, d_{j}\right)+\frac{1}{r_{i}} \phi_{r}\left(r_{i}, \theta_{i}, c_{j}, d_{j}\right)\right.$

$$
\left.+\frac{1}{r_{i}{ }^{2}} \phi_{\theta \theta}\left(r_{i}, \theta_{i}, c_{j}, d_{j}\right)\right]=f\left(r_{i}, \theta_{i}\right)
$$

Dengan mensubstitusi persamaan (20), (21), (23) maka diperoleh persamaan Poisson dalam bentuk persamaan jaringan fungsi radial basis yaitu persamaan (24).

$$
\begin{gathered}
\sum_{j=1}^{m} w_{j}\left[\frac{\left(\theta_{i}-d_{j}\right)^{2}+\beta}{\left(\left(r_{i}-c_{j}\right)^{2}+\left(\theta_{i}-d_{j}\right)^{2}+\beta\right)^{\frac{3}{2}}}\right. \\
\frac{1}{r_{i}} \frac{+}{\sqrt{\left(r_{i}-c_{j}\right)^{2}+\left(\theta_{i}-d_{j}\right)^{2}+\beta}}+
\end{gathered}
$$

$$
\begin{gathered}
\left.\frac{1}{r_{i}{ }^{2}} \frac{\left(r_{i}-c_{j}\right)^{2}+\beta}{\left(\left(r_{i}-c_{j}\right)^{2}+\left(\theta_{i}-d_{j}\right)^{2}+\beta\right)^{\frac{3}{2}}}\right] \\
=f\left(r_{i}, \theta_{i}\right)
\end{gathered}
$$

Pada domain $0<r<a$ dan $0 \leq \theta \leq b$. Dengan kondisi batas pada persamaan (5). Dimana $i=$ $1,2, \ldots, n \operatorname{dan} \beta=\frac{\operatorname{var}\left(r_{i}\right)+\operatorname{var}\left(\theta_{i}\right)}{2}$.

Langkah selanjutnya yaitu menghitung niai bobot $w_{j}$. Persamaan (24) akan digunakan untuk menghitung nilai bobot $w_{j}$.

Misal

$$
\begin{gathered}
A\left(r_{i}, \theta_{i}, c_{j}, d_{j}\right)=\frac{\left(\theta_{i}-d_{j}\right)^{2}+\beta}{\left(\left(r_{i}-c_{j}\right)^{2}+\left(\theta_{i}-d_{j}\right)^{2}+\beta\right)^{\frac{3}{2}}}+ \\
\frac{1}{r_{i}} \frac{r_{i}-c_{j}}{\sqrt{\left(r_{i}-c_{j}\right)^{2}+\left(\theta_{i}-d_{j}\right)^{2}+\beta}}+ \\
\frac{1}{r_{i}^{2}} \frac{\left(r_{i}-c_{j}\right)^{2}+\beta}{\left(\left(r_{i}-c_{j}\right)^{2}+\left(\theta_{i}-d_{j}\right)^{2}+\beta\right)^{2}}
\end{gathered}
$$

Maka persamaan (24) menjadi:

$$
\sum_{j=1}^{m} w_{j} A\left(r_{i}, \theta_{i}, c_{j}, d_{j}\right)=f\left(r_{i}, \theta_{i}\right)
$$

Sehingga, nilai bobot $w_{j}$ dapat diperoleh dengan perhitungan:

$$
w_{j}=A\left(r_{i}, \theta_{i}, c_{j}, d_{j}\right)^{-1} f\left(r_{i}, \theta_{i}\right)
$$

Dengan mensubstitusi nilai-nilai input $\left(r_{i}, \theta_{i}\right)$ ke persamaan (25) dan $f\left(r_{i}, \theta_{i}\right)$ yang didefinisikan dari persamaan Poisson pada koordinat polar yang diaproksimasi, dapat dihitung nilai bobot $w_{j}$. Langkah selanjutnya yaitu menghitung solusi numerik persamaan Poisson dengan cara mengalikan nilai bobot $w_{j}$ dengan fungsi basis multiquadrics 2 variabel yang tanpa diturunkan. Fungsi basis yang digunakan adalah fungsi basis pada persamaan (10). Sehingga, solusi numerik persamaan Poisson (4) adalah:

$$
\hat{u}\left(r_{i}, \theta_{i}\right)=\sum_{j=1}^{m} w_{j} \phi\left(r_{i}, \theta_{i}, c_{j}, d_{j}\right)
$$

Perhitungan galat $\varepsilon_{i}$ diperoleh dengan:

$$
\left[\begin{array}{c}
\varepsilon_{1} \\
\varepsilon_{2} \\
\vdots \\
\varepsilon_{n}
\end{array}\right]=\left|\begin{array}{cc}
u\left(r_{1}, \theta_{1}\right) & \hat{u}\left(r_{1}, \theta_{1}\right) \\
u\left(r_{2}, \theta_{2}\right) & \hat{u}\left(r_{2}, \theta_{2}\right) \\
\vdots & \vdots \\
u\left(r_{n}, \theta_{n}\right) & \hat{u}\left(r_{n}, \theta_{n}\right)
\end{array}\right|
$$

Besarnya galat menunjukkan seberapa dekat solusi eksak dengan solusi numeriknya. 


\section{Simulasi}

Untuk lebih memahami cara kerja metode jaringan fungsi radial basis, akan ditunjukkan simulasi solusi numerik persamaan Poisson pada koordinat polar. Persamaan Poisson pada koordinat polar yang akan diselesaikan adalah:

$$
\begin{aligned}
& \frac{\partial^{2} u(r, \theta)}{\partial r^{2}}+\frac{1}{r} \frac{\partial u(r, \theta)}{\partial r}+\frac{1}{r^{2}} \frac{\partial^{2} u(r, \theta)}{\partial \theta^{2}}= \\
& -3 \cos \theta, \\
& 0<r<1 \text { dan } 0 \leq \theta \leq 2 \pi
\end{aligned}
$$

Dengan kondisi batas

$$
\begin{aligned}
& u(1, \theta)=0 \\
& u(0, \theta)=0
\end{aligned}
$$

Domain pada persamaan (28) kemudian dipartisi menjadi beberapa data diskrit, dengan $\Delta r=0,05$ dan $\Delta \theta=\frac{\pi}{12}$.

Langkah pertama untuk menghitung solusi numerik persamaan Poisson (28) dengan kondisi batas (29) menggunakan jaringan fungsi radial basis adalah diskritisasi domain. Domain persamaan Poisson kemudian dipartisi dengan $\Delta r=0,05$ dan $\Delta \theta=\frac{\pi}{12} . \theta_{i}$ tersebut masih dalam satuan derajat $\left(^{\circ}\right)$, sehingga dirubah terlebih dahulu ke dalam satuan radian supaya dapat dioperasikan dengan $r_{i}$. Setelah memperoleh $r_{i}$ dan $\theta_{i}$ yang telah sama penyebutnya, maka domain pada persamaan Poisson dapat digambarkan dengan gambar 3 berikut:

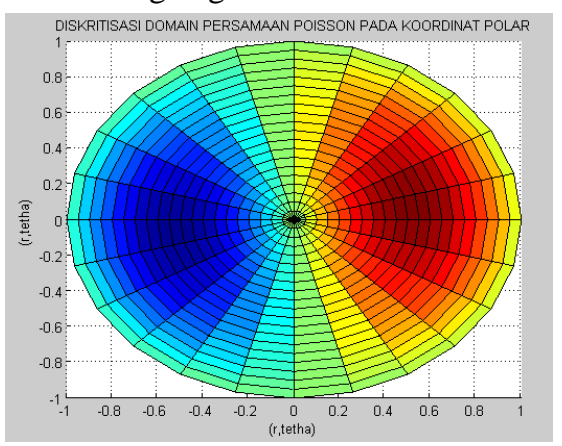

Gambar 3 Diskritisasi Domain Persamaan Poisson

Setelah membagi domain menjadi beberapa titik diskrit, kemudian persamaan Poisson (28) akan dirubah menjadi persamaan jaringan fungsi radial basis, yaitu pada persamaan (30):

$$
\begin{aligned}
& \sum_{j=1}^{525} w_{j}\left[\frac{\left(\theta_{i}-d_{j}\right)^{2}+\beta}{\left[\left(\left(r_{i}-c_{j}\right)^{2}+\left(\theta_{i}-d_{j}\right)^{2}+\beta\right)^{\frac{3}{2}}\right.}\right. \\
& +\frac{1}{r_{i}} \frac{r_{i}-c_{j}}{\sqrt{\left(r_{i}-c_{j}\right)^{2}+\left(\theta_{i}-d_{j}\right)^{2}+\beta}} \\
& \left.+\frac{1}{r_{i}^{2}} \frac{\left(r_{i}-c_{j}\right)^{2}+\beta}{\left(\left(r_{i}-c_{j}\right)^{2}+\left(\theta_{i}-d_{j}\right)^{2}+\beta\right)^{\frac{3}{2}}}\right] \\
& =-3 \cos \theta_{i}
\end{aligned}
$$

Dengan kondisi batas pada persamaan (29) yaitu $u(1, \theta)=0$ dan $u(0, \theta)=0$. Artinya, ketika $r_{i}=$ 0,00 dan $r_{i}=1,00$ maka ruas kanan pada persamaan
(30) sama dengan 0 atau $f\left(0, \theta_{i}\right)=0$ dan $f\left(1, \theta_{i}\right)=$ 0 .

Langkah selanjutnya, yaitu menghitung nilai bobot $w_{j}$. Nilai bobot $w_{j}$ dihitung dengan persamaan (25):

$$
w_{j}=A\left(r_{i}, \theta_{i}, c_{j}, d_{j}\right)^{-1} f\left(r_{i}, \theta_{i}\right)
$$

Dengan $i=1,2, \cdots, 525$ dan $j=1,2, \cdots, 525$.

Himpunan fungsi basis $A\left(r_{i}, \theta_{i}, c_{j}, d_{j}\right)$ yang berbentuk matriks $525 \times 525$ dan himpunan $f\left(r_{i}, \theta_{i}\right)$ yang berbentuk matriks $525 \times 1$ diperoleh dengan mensubstitusikan nilai-nilai input $r_{i}, \theta_{i}, c_{j}, d_{j}$ ke dalam persamaan (25). Kemudian diperoleh nilainilai bobot $w_{j}$ yang berbentuk matriks $525 \times 1$.

Solusi numerik persamaan Poisson (28) dapat dihitung dengan persamaan (31) berikut:

$$
\widehat{u}\left(r_{i}, \theta_{i}\right)=\sum_{j=1}^{525} w_{j} \phi\left(r_{i}, \theta_{i}, c_{j}, d_{j}\right)
$$

Hasil simulasi solusi numerik persamaan (28) dengan kondisi batas (29) kemudian diperoleh $\hat{u}\left(r_{i}, \theta_{i}\right)$ seperti dalam gambar 4 berikut:

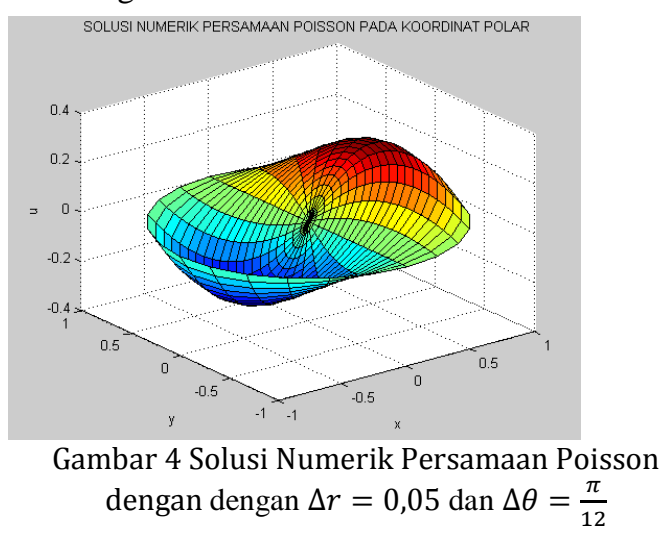

Simulasi solusi numerik persamaan Poisson tersebut dilakukan dengan program Matlab 2008R.

Persamaan Poisson pada koordinat polar $(r, \theta)$, domainnya berbentuk lingkaran. Persamaan ini menggambarkan distribusi panas atau penyebaran panas dalam suatu ruang dengan keadaan steady state atau tetap. Panas dalam suatu ruang yang berbentuk lingkaran menyebar tanpa ada pengaruh waktu, atau dapat dikatakan waktu=konstan.

Gambar 4 mendeskripsikan bahwa panas menyebar pada seluruh ruang/ domain yang berbentuk lingkaran dengan jari-jari 1 . Kondisi pada batas persamaan ini adalah untuk $u(1, \theta)=0$ dan untuk $u(0, \theta)=0$. Artinya, pada saat $r_{i}=1$ dan $r_{i}=$ 0 , suhu/ panas ruang adalah sebesar 1 satuan panas.

Gambar 4 juga menjelaskan bahwa panas menyebar dari $r=0$ ke $r=1$. Dan pada saat tertentu, panas dalam keadaan meningkat/ suhu naik yaitu pada saat $r=0,3$ sampai $r=0,7$. Dari gambar tersebut terlihat bahwa suhu tertinggi ketika grafik berwarna coklat tua yaitu pada $r=0,3$. Suhu terendah terlihat ketika grafik berwarna biru tua yaitu $r=-0,3$ sampai $r=-0,7$. Dengan kondisi batas yang diketahui adalah $u(1, \theta)=0$ dan $u(0, \theta)=0$, 
artinya suhu di pusat lingkaran/ pusat ruang sama dengan suhu di batas/ tepi ruang yang pada kasus ini berbentuk lingkaran.

Perhitungan galat dilakukan untuk mengetahui seberapa dekat solusi analitik atau solusi eksak dengan solusi numeriknya. Galat diperoleh dari selisih antara solusi eksak dan solusi numeriknya. Solusi eksak dari persamaan Poisson pada koordinat polar $\frac{\partial^{2} u(r, \theta)}{\partial r^{2}}+\frac{1}{r} \frac{\partial u(r, \theta)}{\partial r}+\frac{1}{r^{2}} \frac{\partial^{2} u(r, \theta)}{\partial \theta^{2}}=-3 \cos \theta$ dengan domain $0<r<1$ dan $0 \leq \theta \leq 2 \pi$ pada kondisi batas $u(1, \theta)=0$ dan $u(0, \theta)=0$ tersebut diketahui dalam artikel yang ditulis oleh R. C. Mittal dan S. Gahlaut [4]:

$$
\begin{aligned}
u(r, \theta) & =r(1-r) \cos \theta \\
& =\left(r-r^{2}\right) \cdot \cos \theta \\
& =\left(r \cos \theta-r^{2} \cos \theta\right) \\
& u(r, \theta)=r \cos \theta-r^{2} \cos \theta
\end{aligned}
$$

Solusi eksak persamaan Poisson (28) dengan kondisi batas (29) dapat dilihat pada gambar 5 berikut:

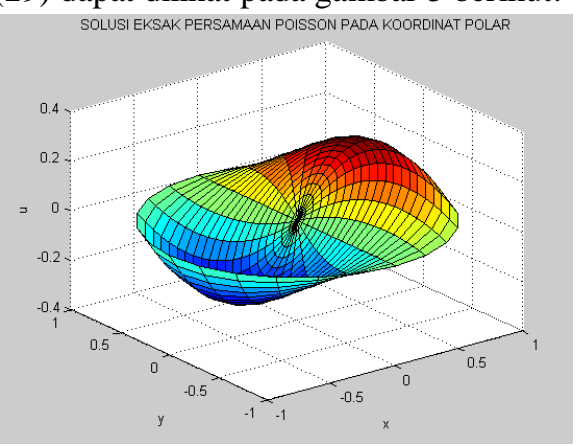

Gambar 5 Solusi Eksak Persamaan Poisson Persamaan Poisson dengan dengan $\Delta r=0,05$ dan $\Delta \theta=\frac{\pi}{12}$

Galat solusi numerik persamaan Poisson (3.37) menggunakan metode jaringan fungsi radial basis dihitung dari persamaan (3.43) berikut:

$$
\left[\begin{array}{c}
\varepsilon_{1} \\
\varepsilon_{2} \\
\vdots \\
\varepsilon_{525}
\end{array}\right]=\left|\begin{array}{c}
u\left(r_{1}, \theta_{1}\right) \\
u\left(r_{2}, \theta_{2}\right) \\
\vdots \\
u\left(r_{525}, \theta_{525}\right) \\
\widehat{u}\left(r_{1}, \theta_{1}\right) \\
-\quad \widehat{u}\left(r_{2}, \theta_{2}\right) \\
\vdots \\
\widehat{u}\left(r_{525}, \theta_{525}\right)
\end{array}\right|
$$

Dan hasil perhitungannya dapat dilihat pada gambar 6 berikut:

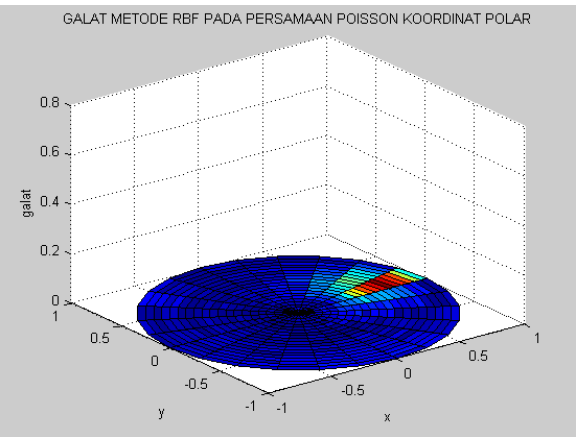

Gambar 6 Galat Jaringan Fungsi Radial Basis ketika

$$
\Delta r=0,05 \text { dan } \Delta \theta=\frac{\pi}{12}
$$

Galat mutlak maksimum diketahui dari program matlab yaitu 0,0012 .

Menganalisis galat metode jaringan fungsi radial basis pada solusi numerik persamaan Poisson pada domain lingkaran (28) dilakukan beberapa simulasi lagi dengan memperbesar dan memperkecil $\Delta r$ serta $\Delta \theta$. Simulasi kedua dilakukan dengan memperbesar $\Delta r$ dan $\Delta \theta$. Solusi numerik persamaan Poisson (28) dengan kondisi batas (29) untuk $\Delta r=$ 0,1 dan $\Delta \theta=\frac{\pi}{6}$ dilakukan dengan program Matlab. Gambar solusi numerik, solusi eksak, dan galatnya dapat dilihat pada gambar 7, 8, dan 9 berikut:

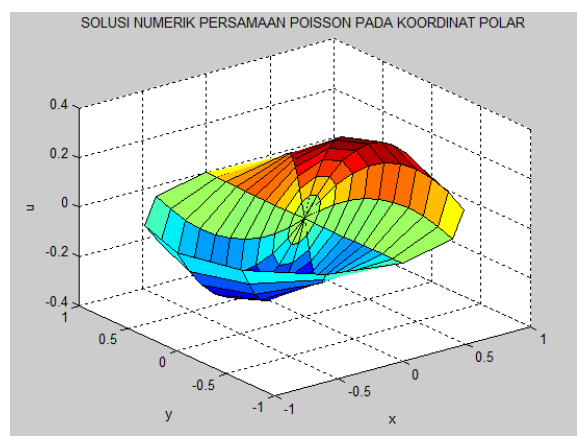

Gambar 7 Solusi Numerik Persamaan Poisson Persamaan Poisson dengan dengan $\Delta r=0,1$ dan $\Delta \theta=\frac{\pi}{6}$

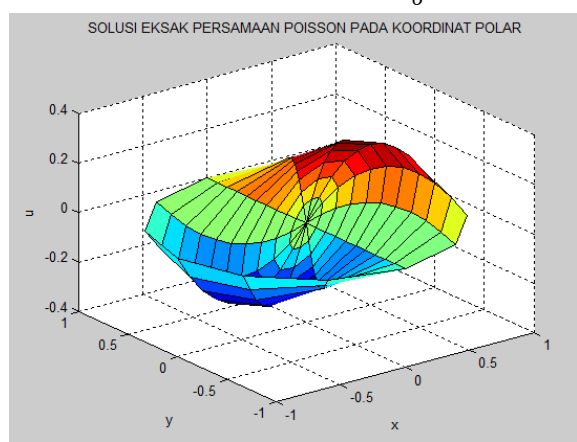

Gambar 8 Solusi Eksak Persamaan Poisson Persamaan Poisson dengan dengan $\Delta r=0,1$ dan $\Delta \theta=\frac{\pi}{6}$

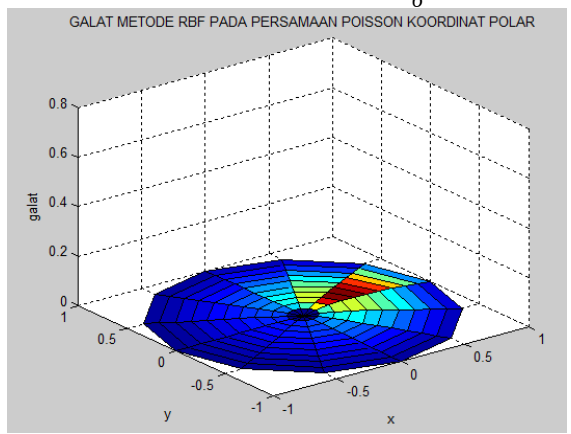

Gambar 9 Galat Jaringan Fungsi Radial Basis ketika $\Delta r=$ 0,1 dan $\Delta \theta=\frac{\pi}{6}$

Galat mutlak maksimum diketahui dari program matlab yaitu 0,0219 .

Simulasi ketiga dilakukan dengan memperkecil $\Delta \theta$. Solusi numerik persamaan Poisson 
(28) dengan kondisi batas (29) untuk $\Delta r=0,05$ dan $\Delta \theta=\frac{\pi}{45}$ dilakukan dengan program Matlab. Gambar solusi numerik, solusi eksak, dan galatnya dapat dilihat pada gambar 10, 11, dan12 berikut:

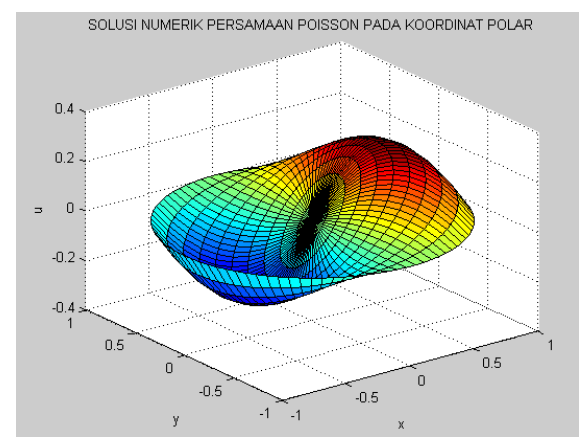

Gambar 10 Solusi Numerik Persamaan Poisson dengan

$$
\Delta r=0,1 \text { dan } \Delta \theta=\frac{\pi}{45}
$$

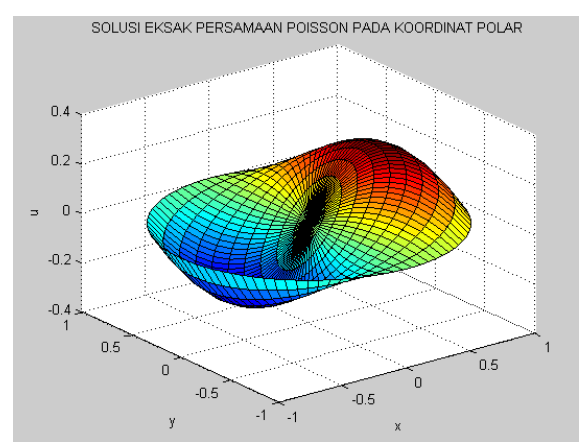

Gambar 11 Solusi Eksak Persamaan Poisson dengan $\Delta r=$ 0,1 dan $\Delta \theta=\frac{\pi}{45}$

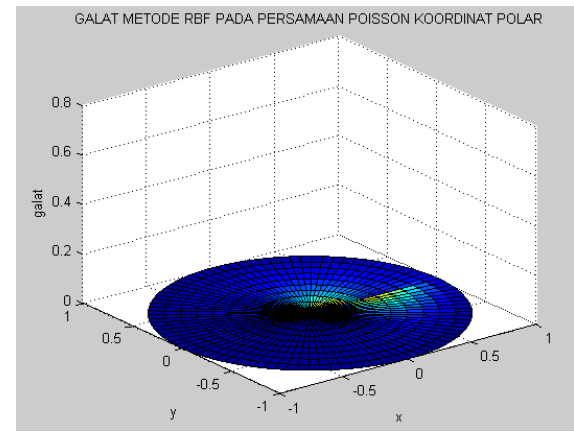

Gambar 12 Galat Metode Jaringan Fungsi Radial Basis ketika $\Delta r=0,1$ dan $\Delta \theta=\frac{\pi}{45}$

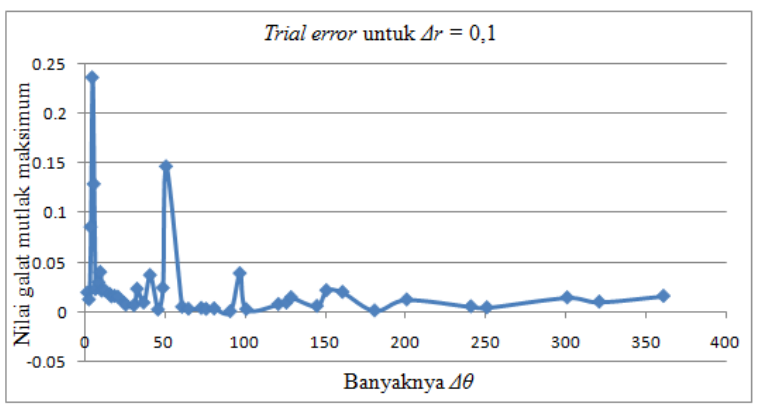

Gambar 13 Trial Error untuk $\Delta r=0,1$
Galat mutlak maksimum diketahui dari program matlab yaitu 0,00088. Kemudian dilakukan beberapa simulasi lagi untuk mengetahui hasil galat yang diperoleh. Dengan pemilihan $\Delta r=0,1$ dan $\Delta \theta$ yang berbeda-beda, diperoleh hasil trial error dari beberapa simulasi yang telah dilakukan pada gambar 13 diatas.

Hasil-hasil trial error tersebut, menunjukkan bahwa besarnya galat mutlak maksimum belum tentu dipengaruhi oleh banyaknya iterasi yang dilakukan. Semakin banyak iterasi yang disebabkan oleh dengan $\Delta r$ dan $\Delta \theta$ yang kecil, belum tentu menghasilkan galat mutlak maksimum yang kecil. Begitu pula sebaliknya. Namun dari simulasi yang telah dilakukan, dapat disimpulkan bahwa metode jaringan fungsi radial basis cukup efektif dalam mengaproksimasi persamaan Poisson pada koordinat polar (28) dengan kondisi batas (29) dengan galat mutlak maksimum terkecil yang diperoleh yaitu 0,00088 dari pemilihan $\Delta r=0,1$ dan $\Delta \theta=\frac{\pi}{45}$.

\section{KESIMPULAN}

Berdasarkan hasil pembahasan, dapat diperoleh kesimpulan sebagai berikut:

Solusi numerik persamaan Poisson pada koordinat polar yang diperoleh dalam penelitian ini menunjukkan hasil yang cukup dekat dengan solusi eksaknya galat mutlak maksimum terkecil yang diperoleh yaitu 0,00088 dari pemilihan $\Delta r=0,1$ dan $\Delta \theta=\frac{\pi}{45}$.

Besarnya galat mutlak maksimum belum tentu dipengaruhi oleh banyaknya iterasi yang dilakukan. Semakin banyak iterasi yang disebabkan oleh dengan $\Delta r$ dan $\Delta \theta$ yang kecil, belum tentu menghasilkan galat mutlak maksimum yang kecil. Begitu pula sebaliknya.

\section{REFERENSI}

[1] W.E. Boyce, R.C. DiPrima, C.W. Haines, Elementary differential equations and boundary value problems, Wiley New York, 1992.

[2] D.S. Broomhead, D. Lowe, Radial basis functions, multi-variable functional interpolation and adaptive networks, DTIC Document, 1988.

[3] N. Mai-Duy, T. Tran-Cong, Approximation of function and its derivatives using radial basis function networks, Appl. Math. Model. 27 (2003) 197-220. 
[4] R.C. MITTAL, S. GaHLAUT, A BOUNDARY INTEGRAL FORMULATION FOR POISSON'S EQUATION IN POLAR COORDINATES, Indian J. Pure Appi. Math. 18 (1987) 965-972.

[5] V. Olej, P. Hajek, Municipal creditworthiness modelling by radial basis function neural networks and sensitive analysis of their input parameters, in: Artif. Neural NetworksICANN 2009, Springer, 2009: pp. 505514.

[6] W.A. Strauss, Partial differential equations: An introduction, New York. (1992).

[7] D. Varberg, E.J. Purcell, Kalkulus dan Geometri Analitis Jilid 2, Jakarta Erlangga..(1999). Kalkulus Dan Geom. Anal. Jilid. 1 (1994). 